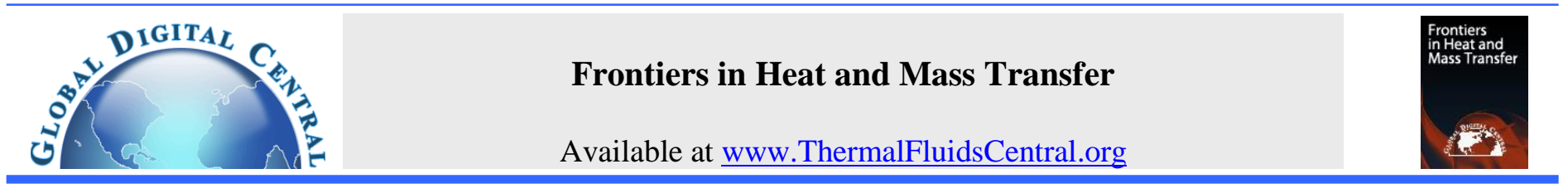

\title{
NUMERICAL AND EXPERIMENTAL INVESTIGATIONS OF NATURAL CONVECTIVE HEAT TRANSFER FROM TWO-SIDED DIAGONALLY INCLINED SQUARE PLATES HAVING A FINITE THICKNESS
}

\author{
Rafiq Manna*, Patrick H. Oosthuizen \\ Queen's University, Kingston, Ontario, K7L 3N6, Canada
}

\begin{abstract}
Natural convective heat transfer from two-sided diagonally inclined square plates having various thicknesses has been numerically and experimentally investigated. The aim of this work is to determine the influence of the plate thickness and diagonal inclination angle on the heat transfer rate for various flow regimes. The mean heat transfer rate was numerically obtained using ANSYS FLUENT@ and experimentally determined using the Lumped Capacity Method. The results indicate that the plate thickness does not have a significant influence on the heat transfer rate while the diagonal inclination angle significantly influences the heat transfer rate especially at higher Rayleigh number values considered.
\end{abstract}

Keywords: Natural Convection, Thick Plate, Diagonally Inclined, Numerical, Experimental

\section{INTRODUCTION}

A numerical study of natural convective heat transfer from the top, bottom and side surfaces of two-sided diagonally inclined square plates with various dimensionless thicknesses (thickness-to-side length ratios) and for various diagonal inclination angles have been conducted for a wide range of Rayleigh number. A limited range of experiments has been undertaken for validation purposes. The upper, lower and side surfaces of the plate are at higher temperature than that of the surrounding fluid. The situation considered is shown in Fig. 1. Mean heat transfer rates from the upper surface, from the lower surface and from the side surface of the plate as well as the mean heat transfer rate averaged over the heated surfaces of the plate have been considered.

Natural convective heat transfer from plates where all surfaces are heated to the same temperature appear in a variety of engineering applications, for example, in cooling of electrical and electronic components. In such applications the heated plate may in some cases be diagonally inclined to the horizontal with a certain inclination angle. The situation considered in the presesnt study is a simplified model of those arising in such engineering applications. However, the results obtained in this study should give an indication of the effects of the diagonal angle of inclination and of the plate thickness in practical situations.

A limited number of numerical and experimental studies of natural convective heat transfer from inclined plates is available, see (Hassan and Mohamed, 1970; Pera and Gebhart, 1973; Al-Arabi and Sakr, 1988; Kobus and Wedekind, 2002; Wei et al., 2002; Corcione et al., 2011; Oosthuizen, 2014). All studies undertaken used air as the surrounding fluid. In these studies, however, only simple forms of inclination have been considered, i.e., situations in which the angle of inclination is with respect to a side of the plate. Furthermore, most of these studies have only considered situations with a limited range of flow conditions, i.e., have only considered laminar flow and situations where only one surface of the plate is heated, i.e., a single-sided plate. An early study of the natural convective heat transfer from the inclined flat surfaces was undertaken by Hassan and Mohamed (1970) who carried out experiments to measure the local heat transfer coefficients along an isothermal flat plate for a laminar flow regime. The plate was single-sided and the range of inclination angles considerd was from horizontal (plate is facing upward) to the horizontal (plate is facing downward) positions. Local Nusselt number variations were correlated in terms of the local Grashof number for various values of the incliation angle. Pera and Gebhart (1973) later analytically and experimentally investigated the natural convective heat transfer above horizontal and slightly inclined surfacses with laminar flow condition being considered. Surface thermal boundary conditions of uniform temperature and uniform heat flux were considered. The similarity solution approach was used to describe the temperature and velocity distributions and the coupled governing equations were integrated numerically. Correlations decribing the local Nusselt numbers for Prandtl numbers near unity were presented for both surface thermal boundary conditions. In addition, the effect of inclination angle on local Nusselt number was shown and compared with the theoretical values for Prandtl number of 0.7. Al-Arabi and Sakr (1988) obtained experimental local and average heat transfer data for natural convective heat transfer from isothermal vertical and inclined single-sided upward-facing plates in both the laminar and the turbulent regions. The range of inclination angles considered was from $0^{\circ}$ to $80^{\circ}$ measured from the vertical. Equations representing the heat transfer results of this study were proposed. More recently, Kobus and Wedekend (2002) performed experiments measuring the natural convective heat transfer form twosided thin circular disks of different thickness-to-diameter ratio at arbirary angles of inclinaton between vertical and horizontal. The authors used their experimental data to develop an imperical correlation for a range of Rayleigh numbers from $2 \times 10^{2}$ to $3 \times 10^{7}$. Wei et al. (2002) undertook a numerical study of the natural convective heat transfer from the upper and lower surfaces of uniformly heated thin plates with various

*Corresponding author. Email: 15rmm1@queensu.ca 
thickness-to-width ratios at arbitrary angles of inclination from horizontal (angles of $0^{\circ}$ to $90^{\circ}$ being considered). The range of Raleigh numbers considered was from $4.8 \times 10^{6}$ to $1.87 \times 10^{8}$. It was concluded that for an inclination angle of less than $10^{\circ}$, the heat transfer characteristics of the upper and lower surfaces are different. Therefore, the average Nusselt number for the upper and lower surfaces were expressed in terms of two different equations, whereas for inclination angle greater than or equal to $10^{\circ}$, the average Nusselt number for the upper and lower surfaces could be adequately correlated by a single equation. Corcione et al. (2011) numerically studied the laminar natural convective heat transfer from an inclined two-sided plate immersed in different fluids and whose sides are simultaneously heated to the same uniform temperature and the situation where one surface was isothermal while the other surface was adiabatic (single-sided case). The range of inclination angles considered was from $0^{\circ}$ to $75^{\circ}$ measured from the vertical, the range of the Rayleigh numbers was from 10 to $10^{7}$ and the range of the Prandtl numbers was from 0.7 to 140. Correlation for the average Nusselt numbers were developed. The average Nusselt numbers for the vertical orientation at different values of Rayleigh and Prandtl numbers were compared with the theoretical solution results given by Churchill and Chu (1975) for a single sided plate and by Hassan and Mohamed (1970) for a two-sided plate with good agreement. Oosthuizen (2014) numerically investigated the natural convective heat transfer from an inclined isothermal single-sided upward-facing square flat plate embedded in a flat adiabatic surrounding surface. The range of inclination angles considered was from $0^{\circ}$ to $30^{\circ}$ measured from the horizontal and the range of Rayleigh numbers was from $10^{5}$ to $10^{13}$. The $k$-epsilon turbulence model was used to obtain the solution and the results showing the variation of the Nusselt numbers with the inclination angles were obtained.

The literature review has demonestrated that there are no available studies to predict the influence of the plate thickness and the diagonal inclination angle on the heat transfer rate from the surfaces of a square plate when it is diagonally inclined to the horizontal. This is basically the goal of the present research.

A summary of this study was presented at the $14^{\text {th }}$ International Conference of Heat Transfer, Fluid Mechanics and Thermodynamics (HEFAT), Wicklow, Ireland, July 22-24, 2019, see (Manna and Oosthuizen, 2019).

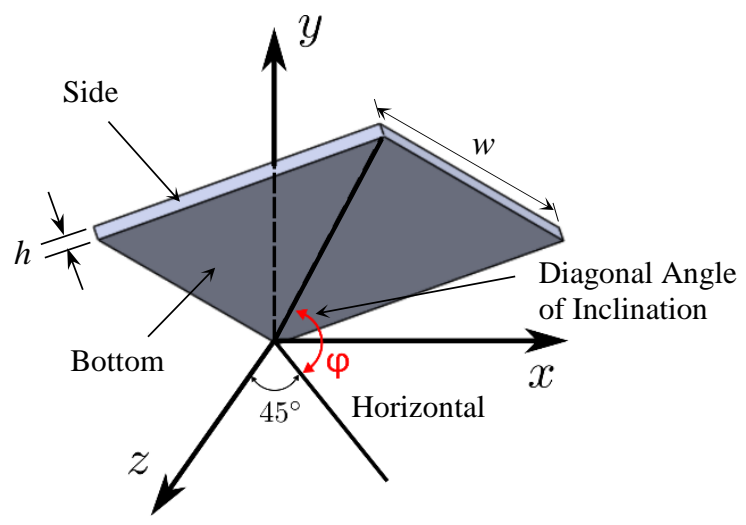

Fig. 1 Finite thickness square plate situation considered. Also shown are the definitions of the plate thickness, $h$, of the bottom (lower) surface and of the side surface of a two-sided plate. The top (upper) surface is above the bottom surface.

\section{NUMERICAL SOLUTION PROCEDURE}

The flow has been assumed to be steady and three dimensional and the fluid properties have been assumed constant except for the density change with temperature which gives the rise to the buoyancy forces, i.e., the Boussinesq approximation has been adopted. The standard $k$-epsilon turbulence model with full account being taken to the buoyancy force effects has been used. This turbulence model has been applied in all calculations and is thus used to determine when transition begins. This approach has been widely used in previous studies, e.g., see (AlbetsChico et al., 2008; Kalendar et al., 2016; Plumb and Kennedy, 1977; Savill, 1993; Schmidt and Patankar, 1991; Xamán et al., 2005). These studies indicate that the results obtained using this approach are of acceptable accuracy for the type of flow situation being considered in the present study. The solution has been obtained by numerically solving the standard continuity, Navier-Stokes, and energy equations using the commercial CFD solver ANSYS FLUENT ${ }^{\odot}$. An extensive gridindependence study using a wide range of numbers of grid points and convergence-criteria independence testing was undertaken, and the heat transfer results presented here are grid and convergence-criteria independent to less than one per cent. Some typical results obtained here in the grid-independence testing are shown in Table 1. These results are for the case of natural convective heat transfer from diagonally inclined square plate which has a dimensionless thickness, $\mathrm{H}$ of zero and at a Rayleigh number of 107 for diagonal inclination angles of $0^{\circ}$ and $30^{\circ}$. The number of nodes used was 2,610,000.

Table 1 Results for the mesh independence study for $\mathrm{H}=0, \mathrm{Ra}=10^{7}$ and $\varphi=0^{\circ}$ and $30^{\circ}$.

\begin{tabular}{cccccc}
\hline $\begin{array}{c}\text { Angle } \\
\text { (degrees) }\end{array}$ & $\begin{array}{c}\text { Rayleigh } \\
\text { number }\end{array}$ & $\begin{array}{c}\text { Number } \\
\text { of nodes }\end{array}$ & $\mathrm{Nu}$ bot & $\mathrm{Nu}$ top & $\mathrm{Nu}$ total \\
\hline 0 & $1 . \mathrm{E}+07$ & 1957500 & 50.6490 & 43.5737 & 47.1113 \\
& & 2272500 & 50.3053 & 41.1845 & 45.7449 \\
& & 2610000 & 48.8119 & 40.0796 & 44.4457 \\
30 & \multirow{2}{*}{$1 . \mathrm{E}+07$} & 1957500 & 52.4275 & 42.1494 & 47.2885 \\
& & 2272500 & 51.6781 & 40.5360 & 46.1070 \\
& & 2610000 & 50.3174 & 39.4418 & 44.8796 \\
& & 2969600 & 50.3844 & 39.3217 & 44.8530 \\
\hline
\end{tabular}

\section{NUMERICAL RESULTS AND DISCUSSION}

The solution has the following parameters:

1. The Rayleigh number, $R a$, based on the side length, $w$, of the square plate and the difference between the plate temperature, $T_{w}$, and the temperature of the fluid far from the plate, $T_{f}$, i.e.:

$$
\mathrm{Ra}=\frac{\beta g w^{3}\left(T_{w}-T_{f}\right)}{v \alpha}
$$

2. Diagonal inclination angle, $\varphi$.

3. Plate dimensionless thickness, $H$, defined by:

$$
\mathrm{H}=h / w
$$

4. The Prandtl number, Pr.

Results have been obtained only for a Prandtl number of 0.74 , which is effectively the value for air. The reason for this is that much of the equipment that is cooled by natural convection uses air as the heat transfer fluid. Diagonal inclination angles of between $0^{\circ}$ and $40^{\circ}$ and Rayleigh numbers between approximately $10^{4}$ and $10^{14}$ have been considered.

The mean heat transfer rate from the top surface, $\overline{Q^{\prime}}$ top , from the bottom surface, ${\overline{Q^{\prime}}}_{\text {bot }}$, and from the side surface, ${\overline{Q^{\prime}}}_{\text {side }}$, of the plate as well as the mean heat transfer rate averaged over all heated surfaces, $\overline{Q^{\prime}}$, have been expressed in terms of a mean Nusselt number based on the side length of the square plate and the difference between the plate temperature and the temperature of the fluid far from the plate. 
The following Nusselt numbers have, therefore, been introduced:

$$
\begin{aligned}
& \mathrm{Nu}_{\text {total }}=\frac{\overline{Q^{\prime} w}}{A_{\text {total }}\left(T_{w}-T_{f}\right) k} \\
& \mathrm{Nu}_{\text {top }}=\frac{\overline{Q^{\prime} \text { top }} w}{A_{\text {plate }}\left(T_{w}-T_{f}\right) k} \\
& \mathrm{Nu}_{\text {bot }}=\frac{\overline{Q^{\prime}} \text { bot } w}{A_{\text {plate }}\left(T_{w}-T_{f}\right) k} \\
& \mathrm{Nu}_{\text {side }}=\frac{\overline{Q^{\prime}}}{A_{\text {side }} w} \\
& A_{\text {side }}\left(T_{w}-T_{f}\right) k
\end{aligned}
$$

where,

$$
{\overline{Q^{\prime}}}^{=}{\overline{Q^{\prime}}}_{\text {top }}+{\overline{Q^{\prime}}}_{\text {bot }}+{\overline{Q^{\prime}}}_{\text {side }}
$$

and where $A_{\text {total }}, A_{\text {plate }}$, and $A_{\text {side }}$ are the total area of the heated surfaces of the plate, the areas of the upper and the lower surfaces of the plate, and the area of the side surface of the plate, respectively.

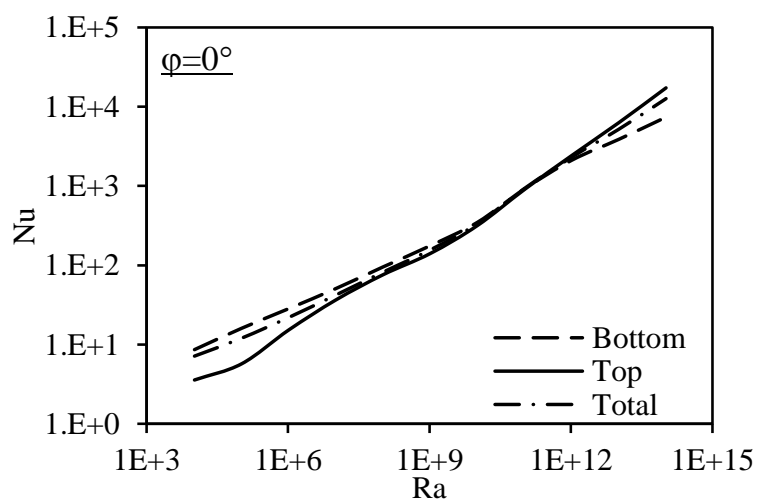

(a)

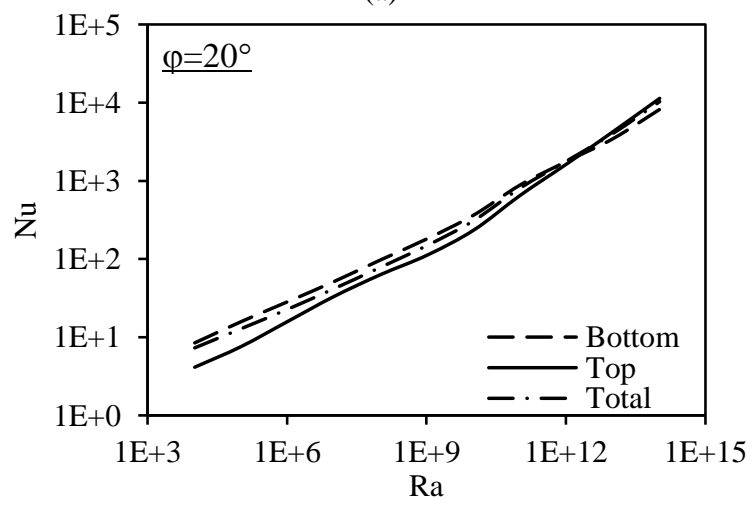

(c)
Therefore:

$A_{\text {total }}=2 A_{\text {plate }}+A_{\text {side }}$

$\mathrm{Nu}_{\text {total }}=\frac{\left(\mathrm{Nu}_{\text {top }}+\mathrm{Nu} \text { bot }\right) A_{\text {plate }}+\mathrm{Nu}_{\text {side }} A_{\text {side }}}{A_{\text {total }}}$

Variations of the mean Nusselt number for the top surface, $N u_{\text {top }}$, for the bottom surface, $N u_{b o t}$, and for all heated surfaces of the plate, $N u_{\text {total }}$, with Rayleigh number for various diagonal inclination angles are shown in Figs. 2 and 3 for the plate dimensionless thickness values of 0.0635 and 0.3 , respectively. The results given in Figs. 2-a and 3-a are for the case where the diagonal inclination angle is $0^{\circ}$, i.e., for the case where the plate is horizontal. It will be seen from the results given in Figs. 2 and 3 that in all cases, i.e., for all angles of inclination, the Nusselt number for the bottom surface is higher than that for the top surface at the lower Rayleigh numbers considered but that in all cases the Nusselt number for the top surface is higher than that for the bottom surface at the higher Rayleigh numbers considered.

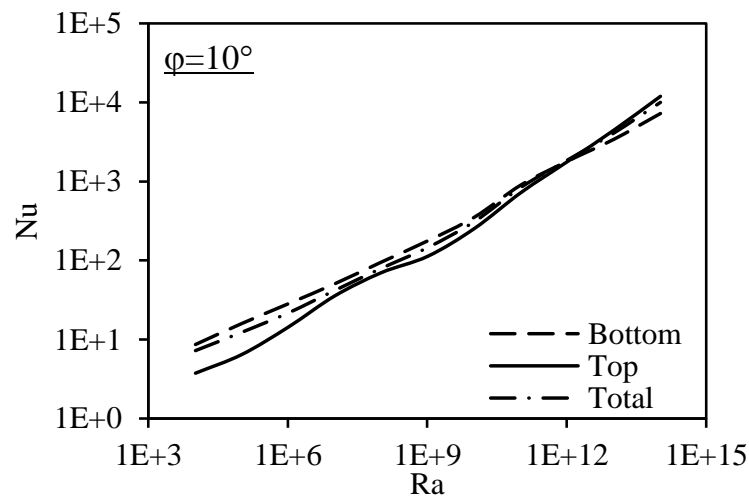

(b)

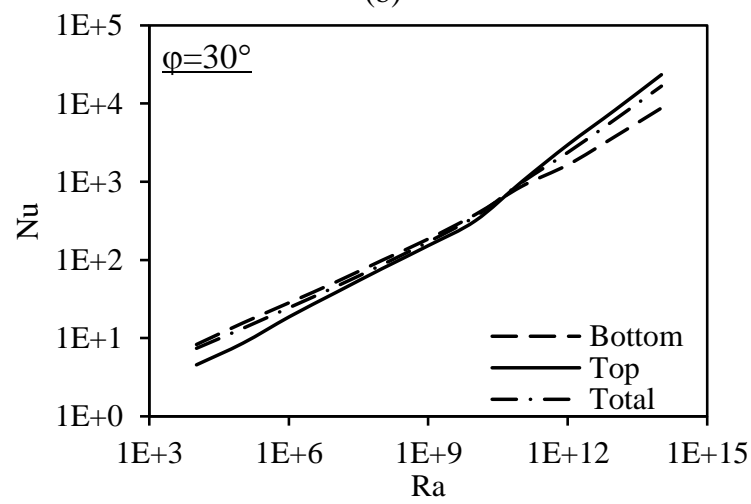

(d)

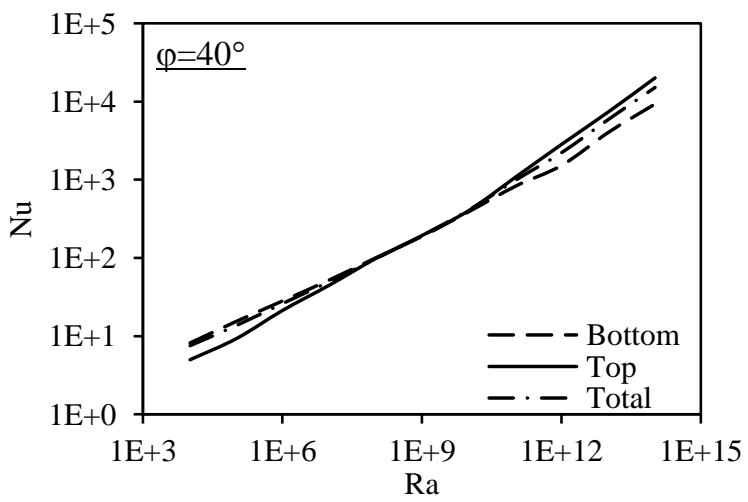

(e)

Fig. 2 Variations of the mean Nusselt number for the bottom surface, the top surface, and for all heated surfaces of the square plate with Rayleigh number for diagonal angles of inclination of (a) $0^{\circ}$, (b) $10^{\circ}$, (c) $20^{\circ}$, (d) $30^{\circ}$, and (e) $40^{\circ}$ for a dimensionless plate thickness, $\mathrm{H}$, of 0.0635 . 


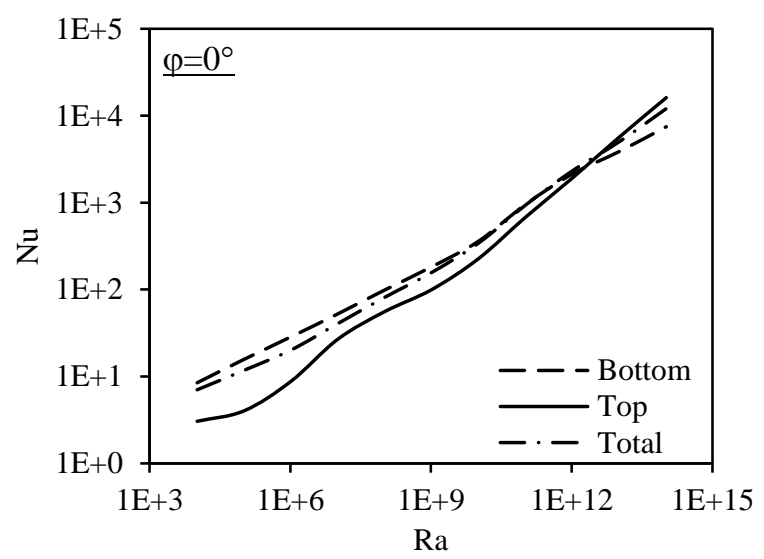

(a)

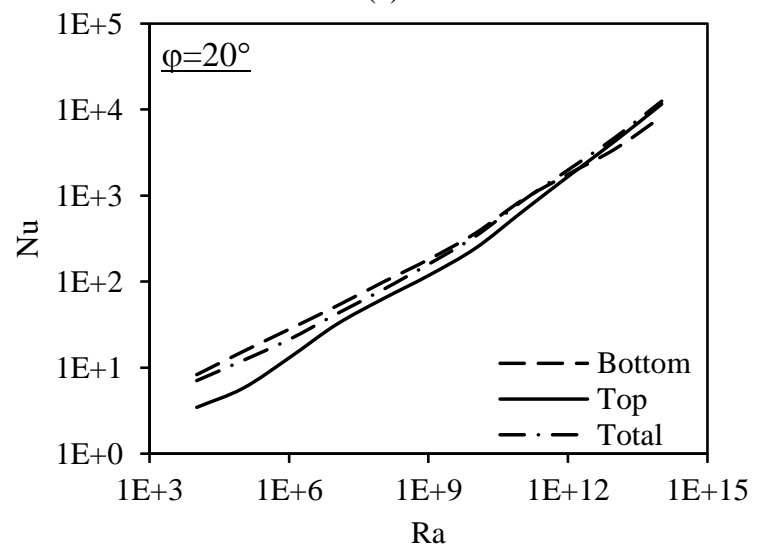

(c)

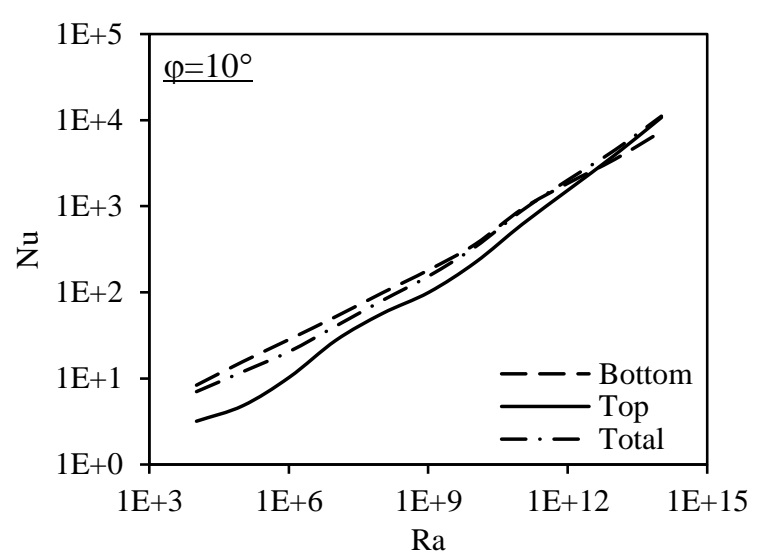

(b)

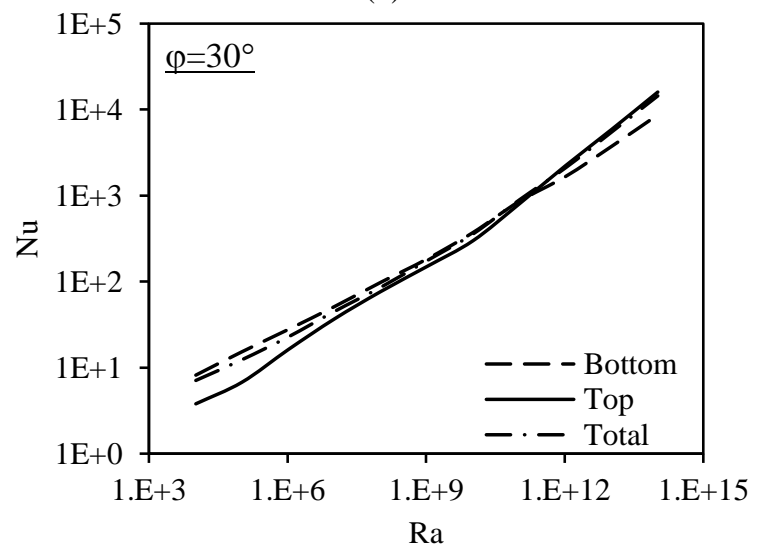

(d)

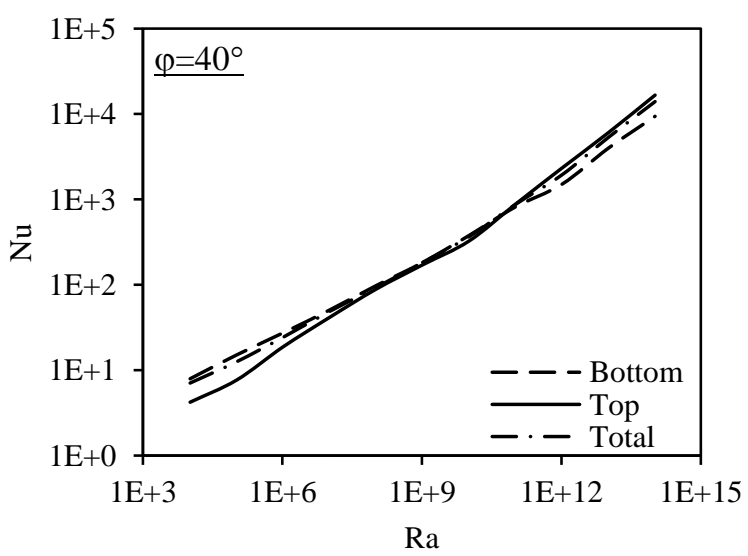

(e)

Fig. 3 Variations of the mean Nusselt number for the bottom surface, the top surface, and for all heated surfaces of the square plate with Rayleigh number for diagonal angles of inclination of (a) $0^{\circ}$, (b) $10^{\circ}$, (c) $20^{\circ}$, (d) $30^{\circ}$, and (e) $40^{\circ}$ for a dimensionless plate thickness, $\mathrm{H}$, of 0.3 .

To further illustrate the effect of the plate dimensionless thickness on the heat transfer rate. Typical variations of the mean Nusselt number for the top and bottom surfaces with dimensionless plate thickness for various Rayleigh number values and for various diagonal inclination angles considered are shown in Fig. 4. It can be seen from this figure that for various diagonal inclination angles considered the dimensionless thickness has an almost negligible effect on the Nusselt number for the bottom surface whereas this effect is significant for the top surface especially at lower values of dimensionless thickness considered, the nature of this effect being dependent on the value of the Rayleigh number. It can be also seen from the figure that for the top surface the Nusselt number decreases with increasing the dimensionless thickness for various diagonal inclination angles considered. Typical variations of the mean Nusselt number with Rayleigh number for the side surface of the plate for the diagonal inclination angles considered are shown in Fig. 5 for two values of dimensionless plate thickness. It will be seen from this figure that for the diagonal inclination angles of $0^{\circ}, 10^{\circ}$ and $20^{\circ}$ (Fig. 5-a, b, c) the dimensionless plate thickness does affect the Nusselt number for the range of Rayleigh numbers considered except at higher values of the Rayleigh number (approximately greater than $10^{10}$ ) where this effect is almost negligible. For the diagonal inclination angles of $30^{\circ}$ and $40^{\circ}$ (Fig. 5 -d, e) the effect of the dimensionless plate thickness on the Nusselt number, however, is significant at lower values of the Rayleigh number (approximately less than $10^{7}$ ) while this effect is negligible for Rayleigh numbers between approximately $10^{7}$ and $10^{10}$. Above Rayleigh number value of approximately $10^{10}$ the dimensionless plate thickness has a modest effect on the Nusselt number. 

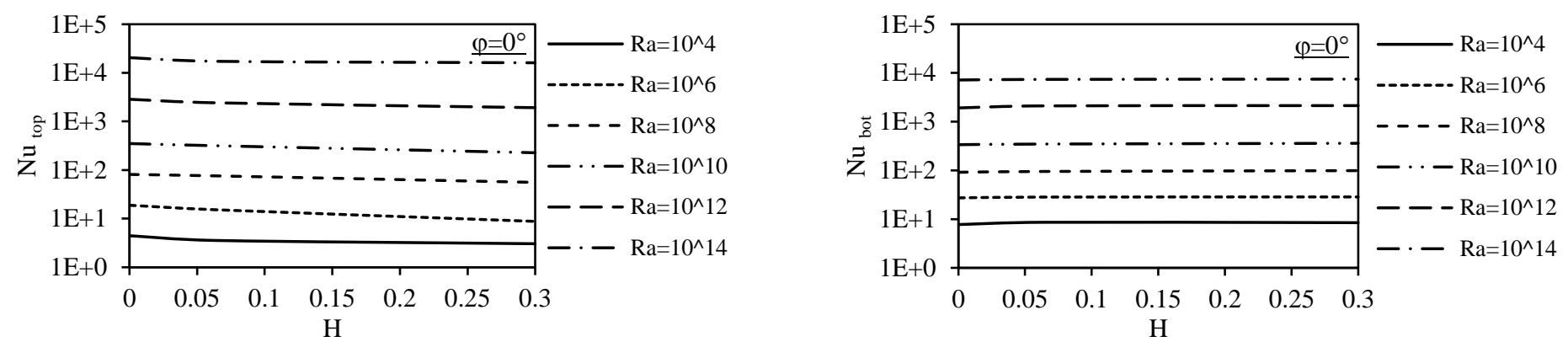

(a) Top surface (left) and bottom surface (right)
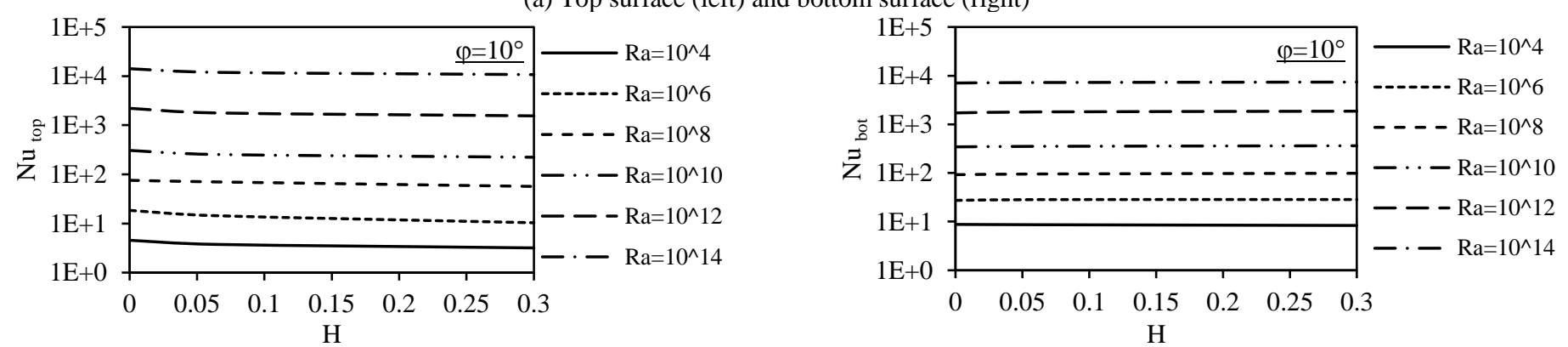

(b) Top surface (left) and bottom surface (right)
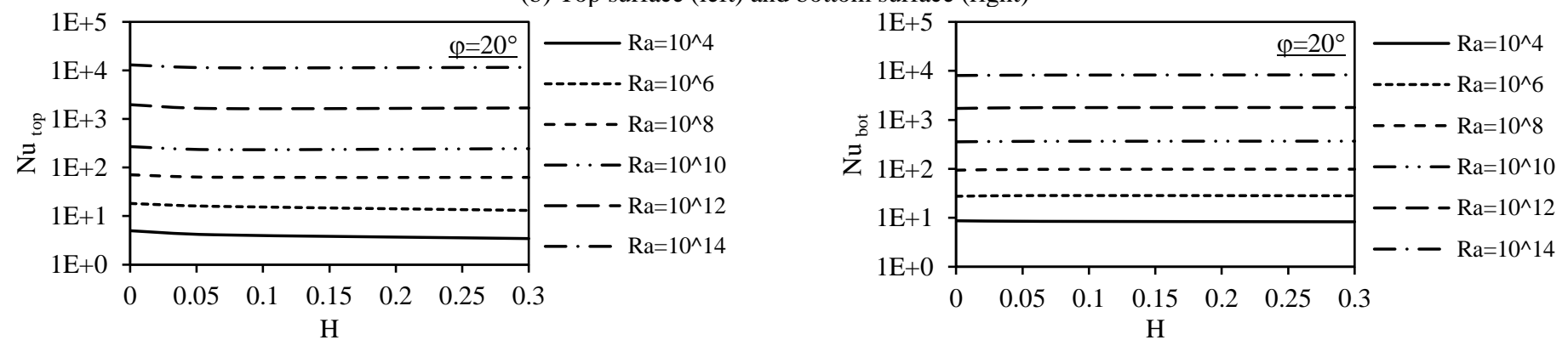

(c) Top surface (left) and bottom surface (right)
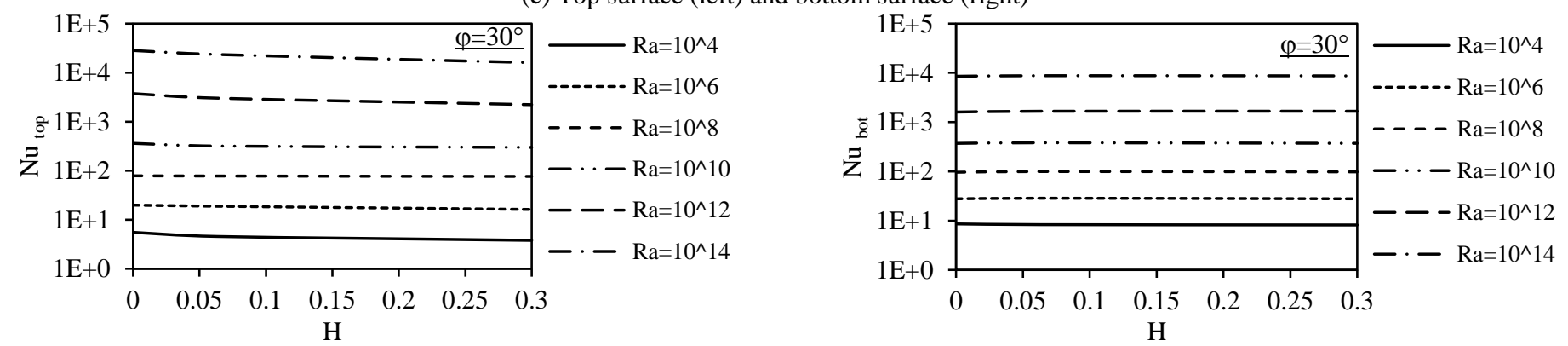

(d) Top surface (left) and bottom surface (right)
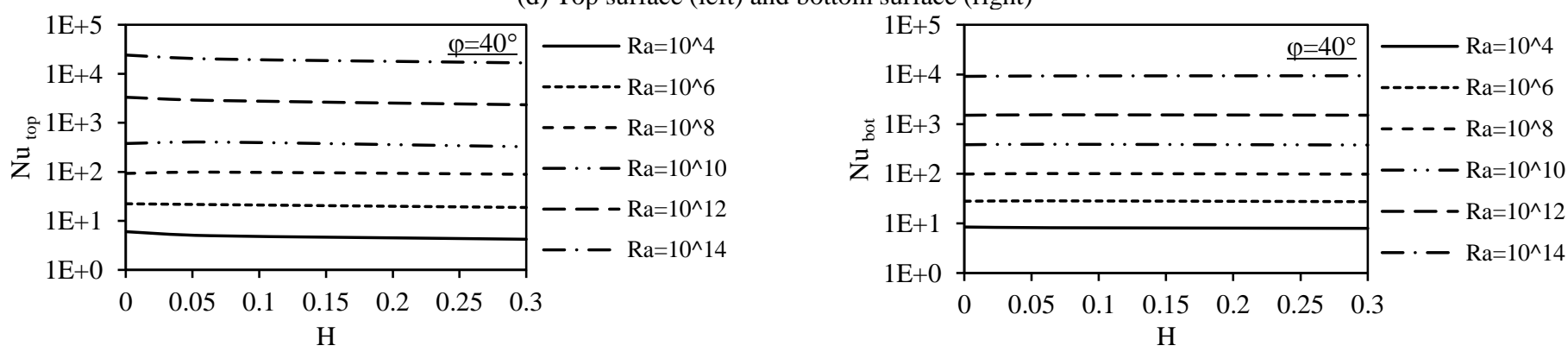

(e) Top surface (left) and bottom surface (right)

Fig. 4 Variations of the mean Nusselt number for the top and bottom surfaces of the square plate with dimensionless plate thickness for various values of Rayleigh number for diagonal inclination angles of (a) $0^{\circ}$, (b) $10^{\circ}$, (c) $20^{\circ}$, (d) $30^{\circ}$, and (e) $40^{\circ}$. 


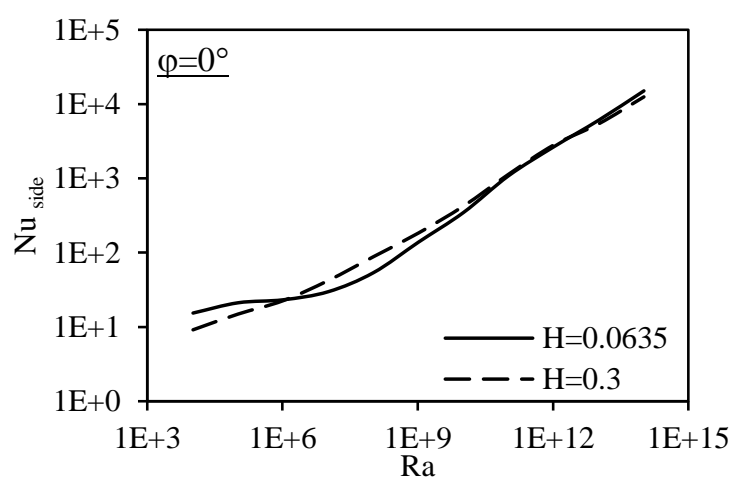

(a)

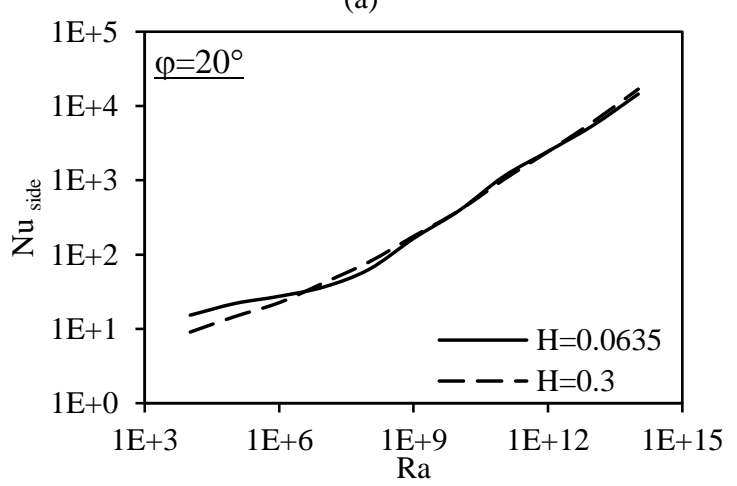

(c)

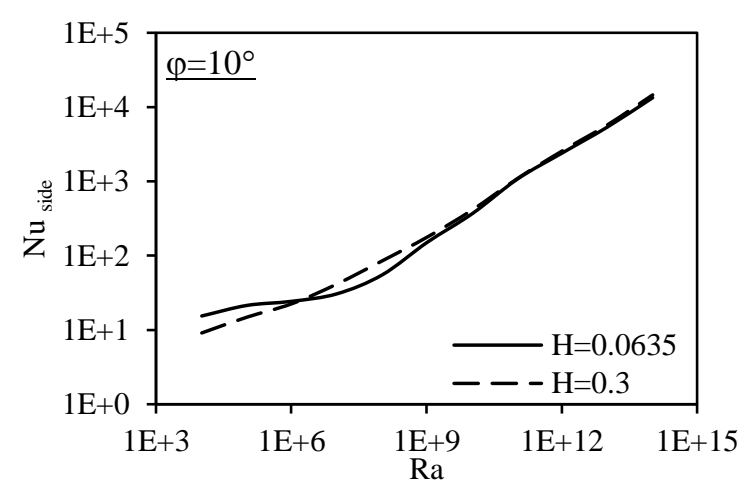

(b)

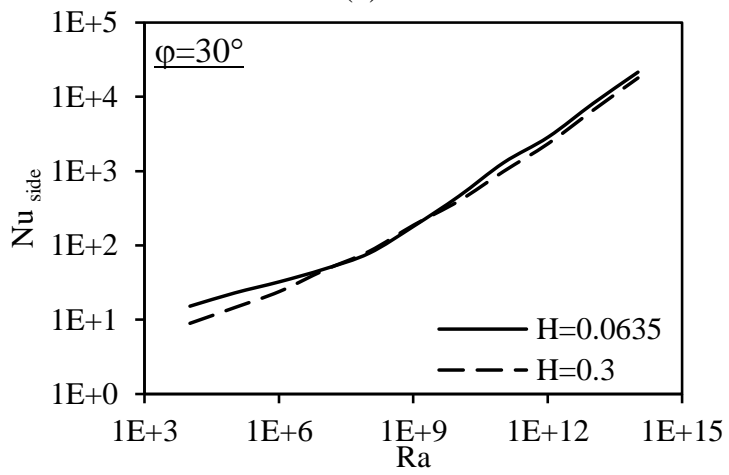

(d)

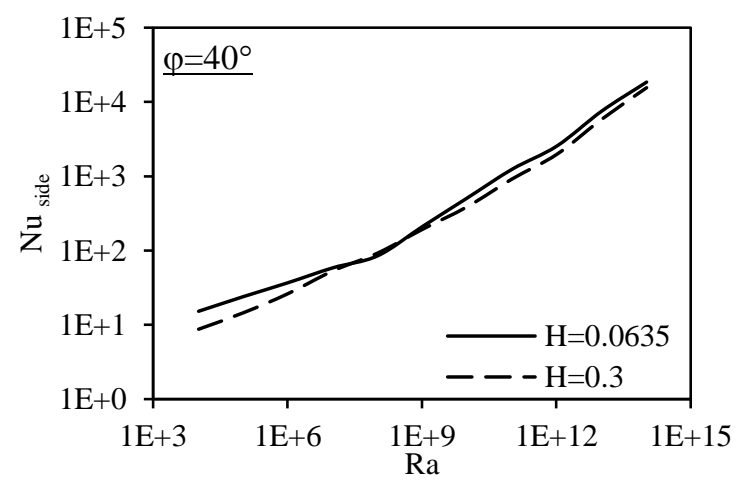

(e)

Fig. 5 Variations of the mean Nusselt number for the side surface of the plate with Rayleigh number for two values of dimensionless plate thickness for diagonal inclination angles of (a) $0^{\circ}$, (b) $10^{\circ}$, (c) $20^{\circ}$, (d) $30^{\circ}$, and (e) $40^{\circ}$.

To more clearly illustrate the influence of the diagonal inclination angle on the heat transfer rate, typical variations of the mean Nusselt number with diagonal inclination angle for the range of Rayleigh number considered for the dimensionless plate thickness of 0.0635 are shown in Figs. 6 and 7 for the top and bottom surfaces, respectively while typical variations for a dimensionless plate thickness of 0.3 are shown in Figs. 8 and 9 for the top and bottom surfaces, respectively. In these figures, the range of Rayleigh numbers considered was divided into three subranges, lower, intermediate and higher values of Rayleigh number. The purpose of this is to more clearly illustrate the influence of the diagonal inclination angle on the heat transfer rate. It will be seen from these figures that for the top surface of the plate which has a dimensionless plate thickness, $\mathrm{H}$, of 0.0635 (Fig. 6) the Nusselt number increases as the diagonal inclination angle increases for Rayleigh number values of $10^{4}$ and $10^{5}$. After Rayleigh number value of $10^{5}$ the Nusselt number first decreases as the angle increases from $0^{\circ}$ and starts to increase as the angle increases above about $10^{\circ}$ for Rayleigh number value of $10^{6}$. For the range of Rayleigh numbers between $10^{7}$ and $10^{11}$ the behavior is almost the same such that the Nusselt number decreases as the diagonal inclination angle increases from $0^{\circ}$ but starts to increase as the angle is above about $20^{\circ}$. For higher values of Rayleigh number, the Nusselt number decreases as the diagonal inclination angle increases from $0^{\circ}$ until about $20^{\circ}$ is reached after which the Nusselt number starts to increase with the angle and then decreases again after about $30^{\circ}$. For the bottom surface, it can be seen from Fig. 7 that the effect of the diagonal inclination angle on the Nusselt number is significantly different from that for the top surface such that this effect is significant only at higher values of Rayleigh number (Fig. 7-c) where the Nusselt number decreases with the diagonal inclination angle for Rayleigh number value of $10^{12}$ whereas for the Rayleigh number values of $10^{13}$ and $10^{14}$ the Nusselt number decreases as the diagonal inclination angle increases from $0^{\circ}$ to about $10^{\circ}$ after which the Nusselt number increases with the diagonal inclination angle. For the plate with a dimensionless thickness, $\mathrm{H}$, of 0.3 , however, it can be noted from the results shown in Fig. 8 that for the top surface the Nusselt number increases with the diagonal inclination angle for a wider range of Rayleigh number (from $10^{4}$ to $10^{9}$ ). The Nusselt number starts to decrease as the diagonal inclination angle increases from $0^{\circ}$ and starts to increase as the angle increases above about $10^{\circ}$ for the other values of Rayleigh number considered. The effect of the diagonal inclination angle on the Nusselt number for the bottom surface for $\mathrm{H}=0.3$ (Fig. 9) is the same as that for $\mathrm{H}=0.0635$ since the dimensionless thickness has an almost negligible effect on the heat transfer rate from the bottom surface. 


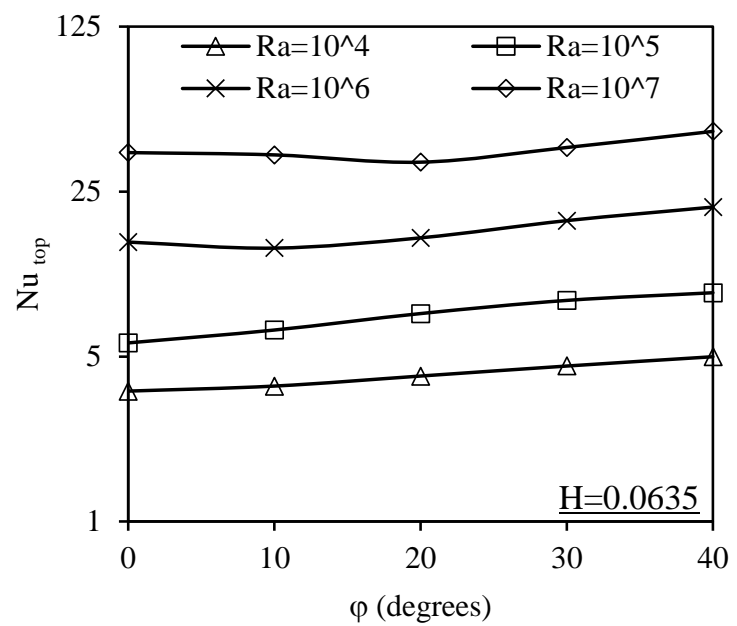

(a)

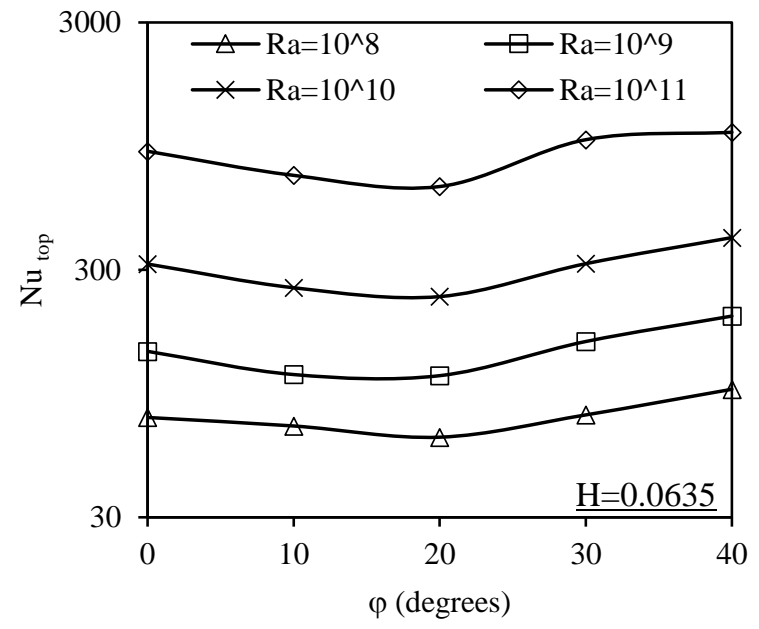

(b)

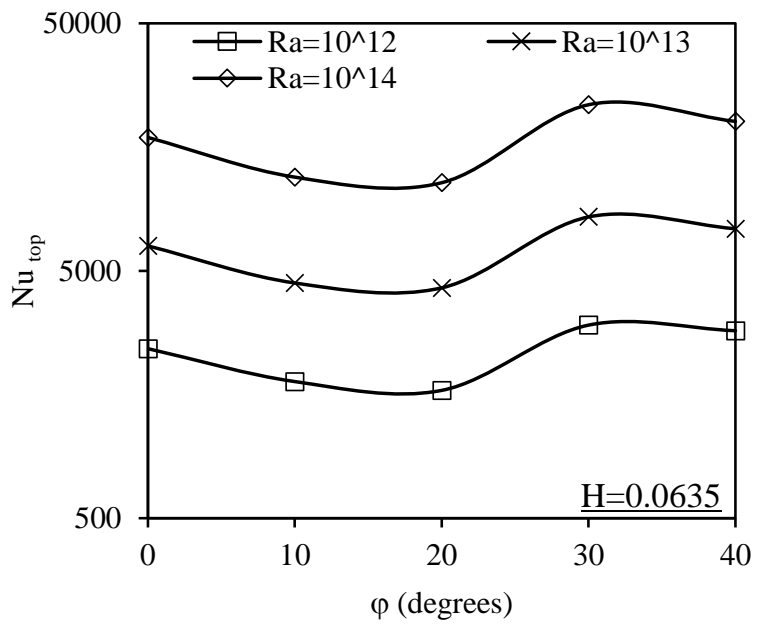

(c)

Fig. 6 Variations of the mean Nusselt number for the top surface of the plate with diagonal inclination angle for (a) lower Rayleigh numbers, (b) intermediate Rayleigh numbers, and (c) higher Rayleigh numbers considered for a dimensionless plate thickness, $\mathrm{H}$, of 0.0635 .

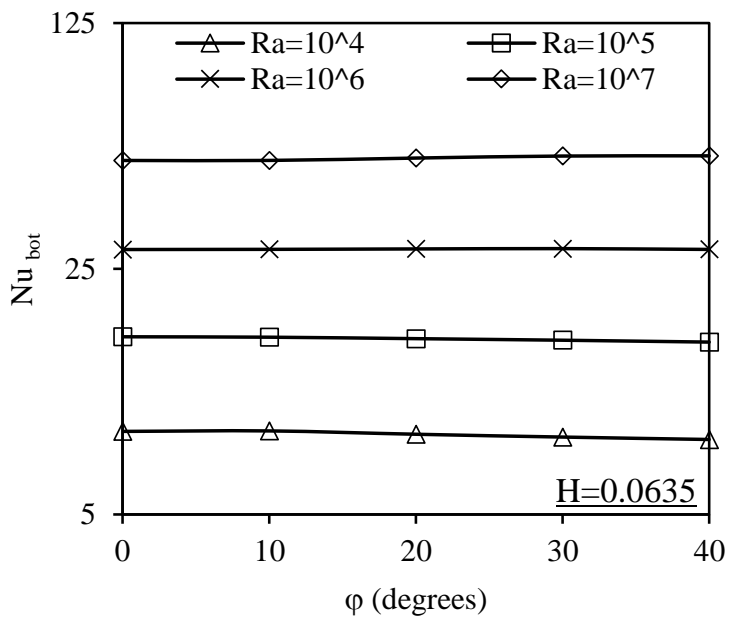

(a)

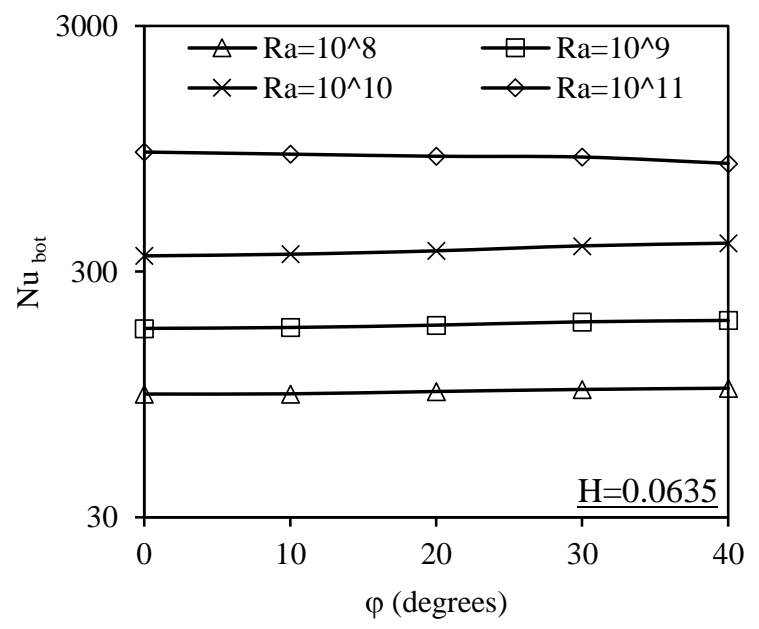

(b)

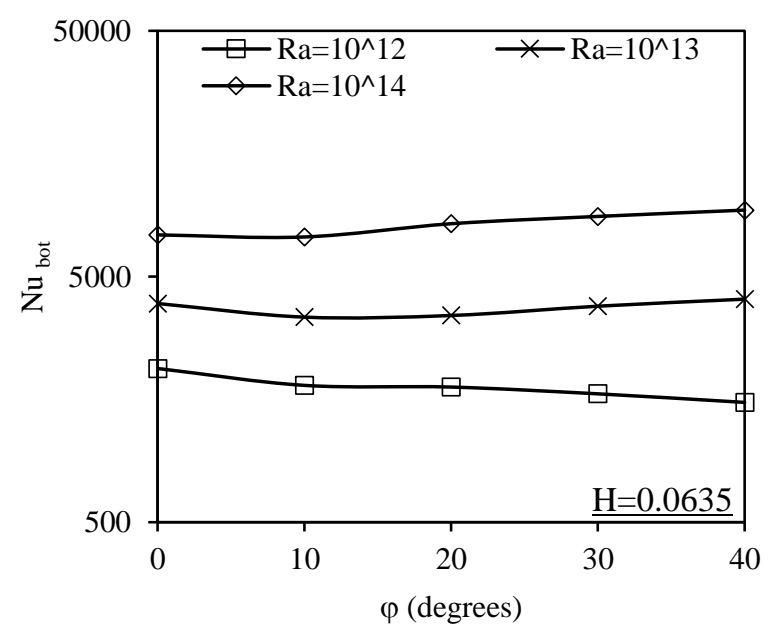

(c)

Fig. 7 Variations of the mean Nusselt number for the bottom surface of the plate with diagonal inclination angle for (a) lower Rayleigh numbers, (b) intermediate Rayleigh numbers and (c) higher Rayleigh numbers considered for a dimensionless plate thickness, $\mathrm{H}$, of 0.0635 . 


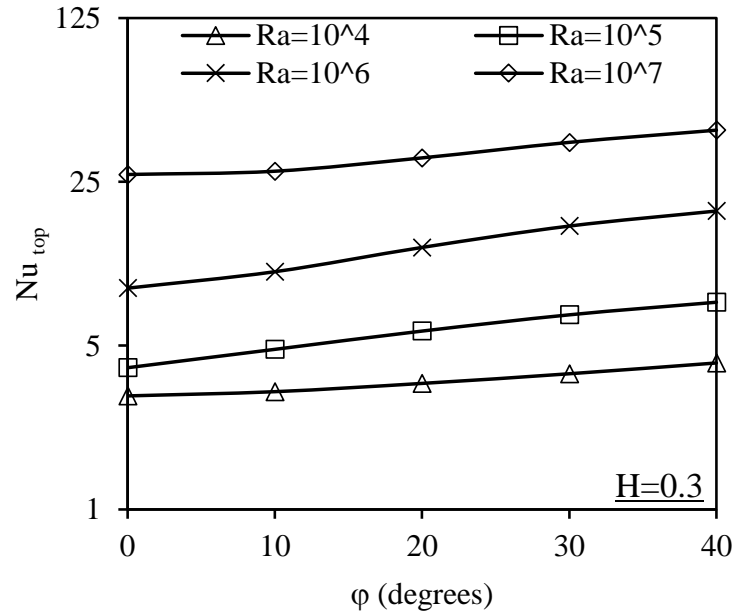

(a)

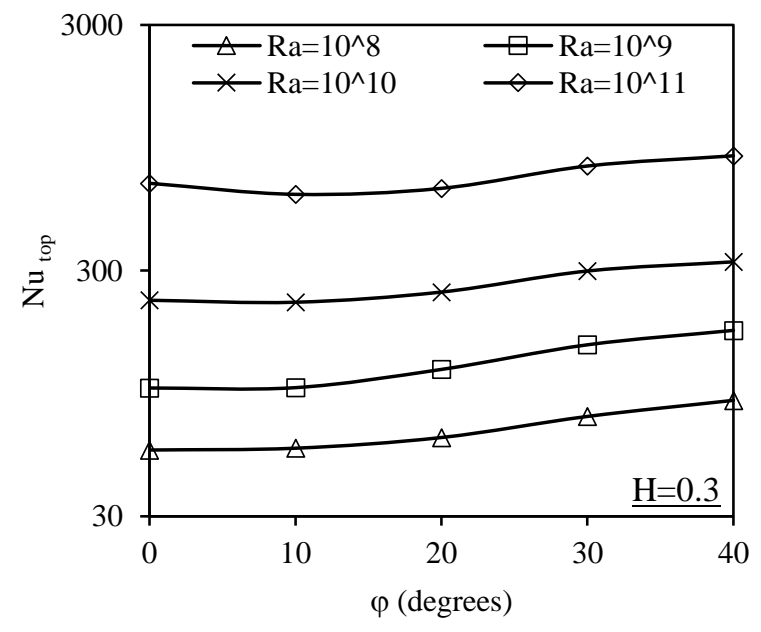

(b)

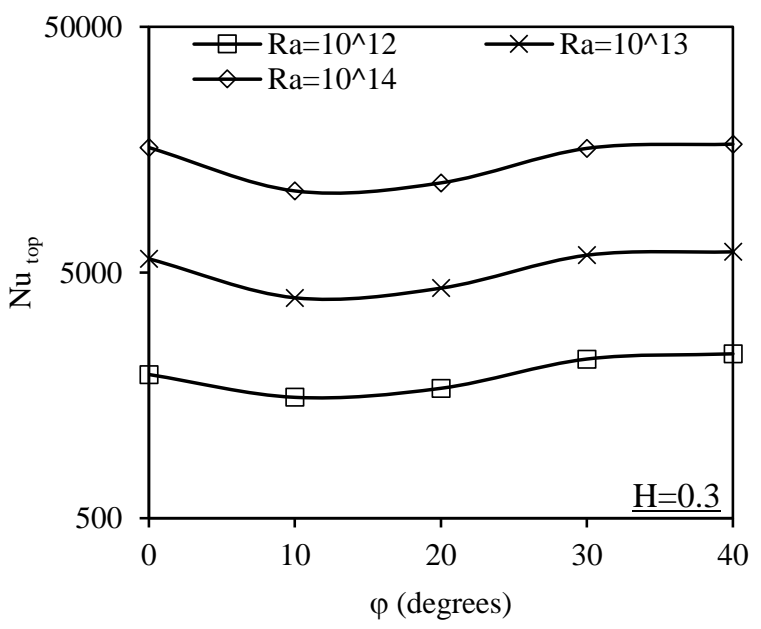

(c)

Fig. 8 Variations of the mean Nusselt number for the top surface of the plate with diagonal inclination angle for (a) lower Rayleigh numbers, (b) intermediate Rayleigh numbers and (c) higher Rayleigh numbers considered for a dimensionless plate thickness, $\mathrm{H}$, of 0.3 .

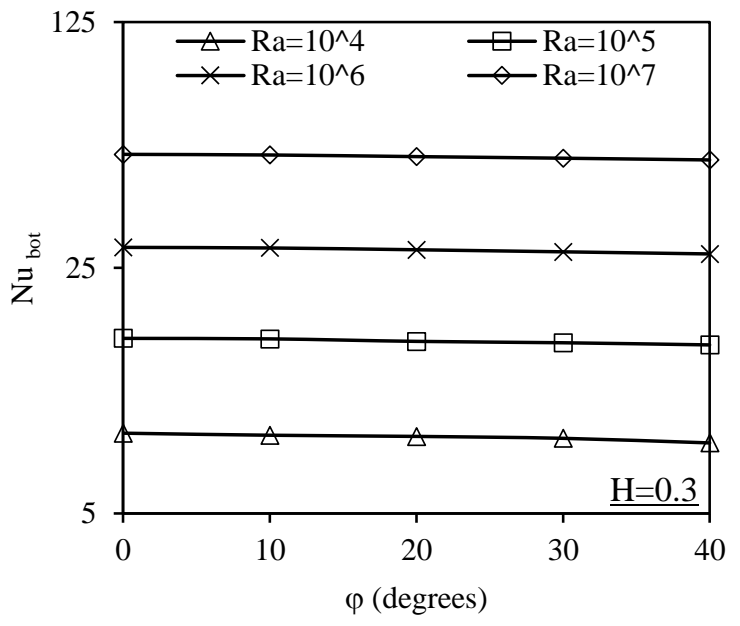

(a)

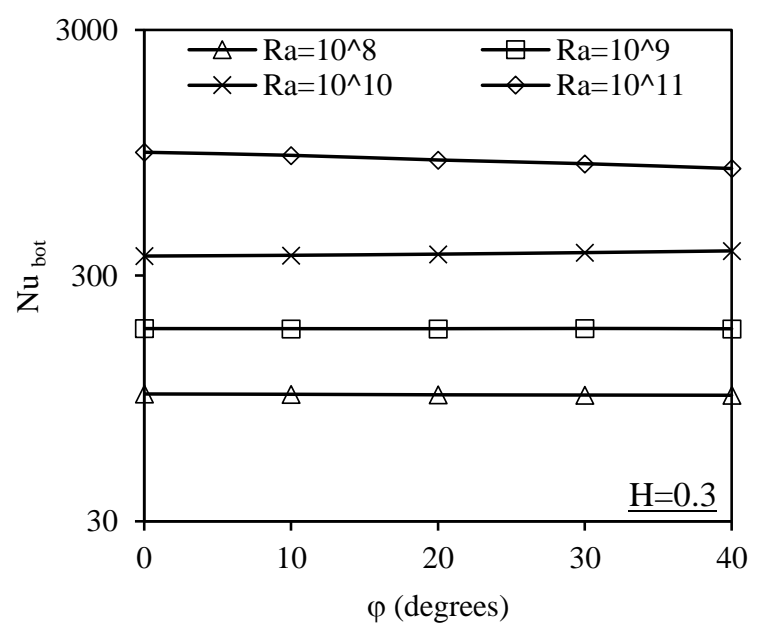

(b)

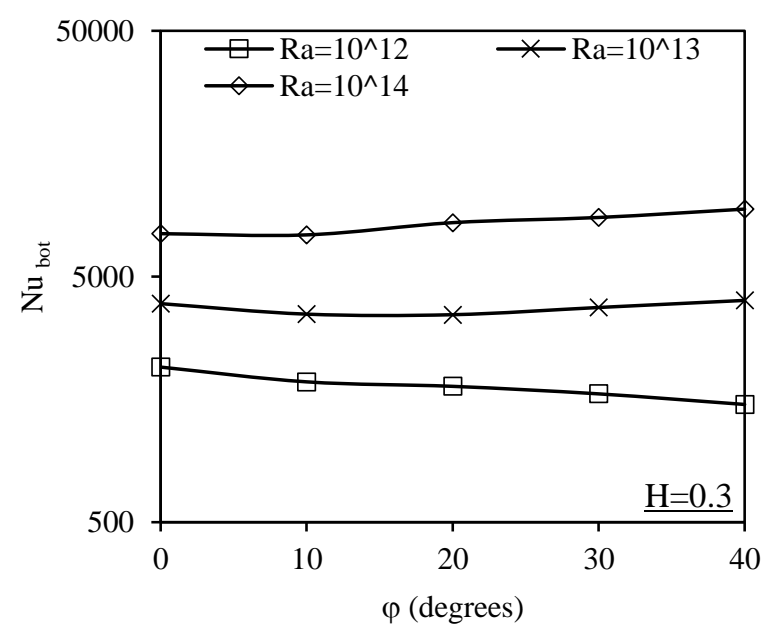

(c)

Fig. 9 Variations of the mean Nusselt number for the bottom surface of the plate with diagonal inclination angle for (a) lower Rayleigh numbers, (b) intermediate Rayleigh numbers and (c) higher Rayleigh numbers considered for a dimensionless plate thickness, $\mathrm{H}$, of 0.3 . 
The influence of the diagonal inclination angle on the heat transfer rate from the side surface of the plate is shown by the typical variations of the mean Nusselt number with the diagonal inclination angle given in Figs. 10 and 11 for the dimensionless thickness values of 0.0635 and 0.3 , respectively. Again, the Rayleigh numbers range was divided into three subranges. It can be seen from Fig. 10 (i.e., at $\mathrm{H}=0.0635$ ) that the influence of diagonal inclination angle starts at Rayleigh number value of about $10^{6}$ and more specifically when the angle is approximately above $10^{\circ}$ where the Nusselt number increases as the diagonal inclination angle increases, this influence being true until the Rayleigh number value of $10^{10}$ after which the influence of the diagonal inclination angle on the Nusselt number becomes significant after about $20^{\circ}$ where the Nusselt number starts to increase with the angle up to about $30^{\circ}$ after which the Nusselt number starts to decrease with the angle. For the dimensionless plate thickness, $\mathrm{H}$, of 0.15 , it can be seen from Fig. 11 that the influence of the diagonal inclination angle on the Nusselt number starts to be significant at Rayleigh number value of about $10^{6}$ and after about $20^{\circ}$, this influence being true up to Rayleigh number value of $10^{8}$. For Rayleigh number values of $10^{9}$ and $10^{10}$, this influence of the diagonal inclination angle on the Nusselt number is almost negligible. The influence of the diagonal inclination angle on the Nusselt number becomes significant again at Rayleigh number value of $10^{11}$. It can be seen from Fig. 11-b, c that the Nusselt number decreases with the diagonal inclination angle for Rayleigh number values of $10^{11}$ and $10^{12}$, whereas for Rayleigh number values of $10^{13}$ and $10^{14}$ it will be noted that the Nusselt number first increases as the angle increases from $0^{\circ}$ then decreases when the angle is approximately above $30^{\circ}$.

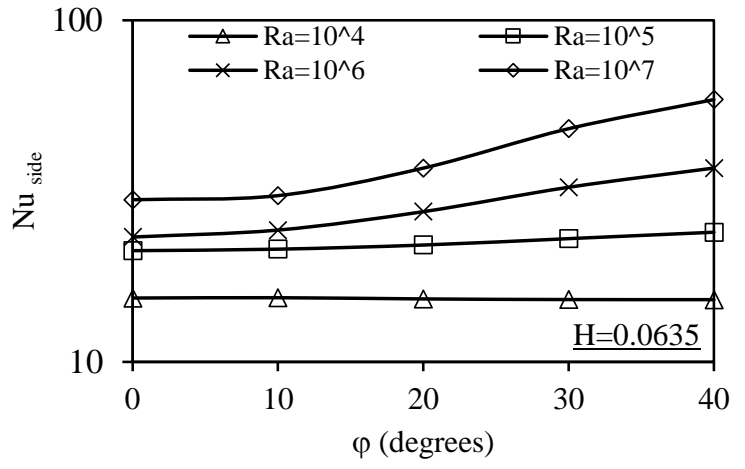

(a)

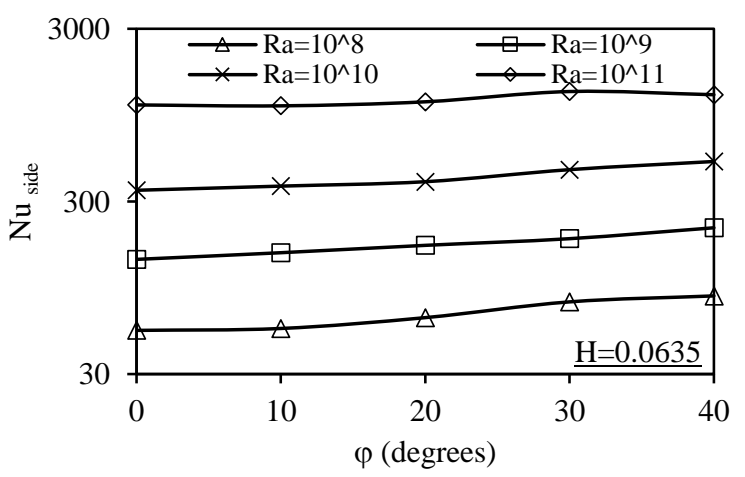

(b)

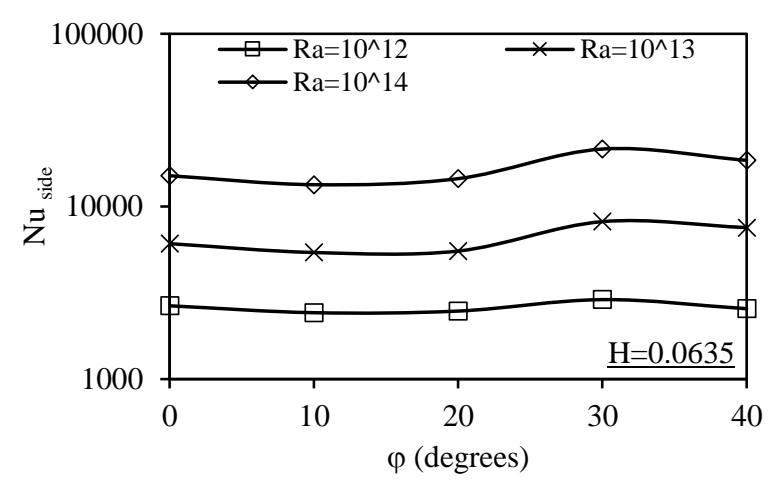

(c)

Fig. 10 Variations of the mean Nusselt number for the side surfaces of the plate with diagonal inclination angle for (a) lower Rayleigh numbers, (b) intermediate Rayleigh numbers and (c) higher Rayleigh numbers considered for a dimensionless plate thickness, $\mathrm{H}$, of 0.0635 .

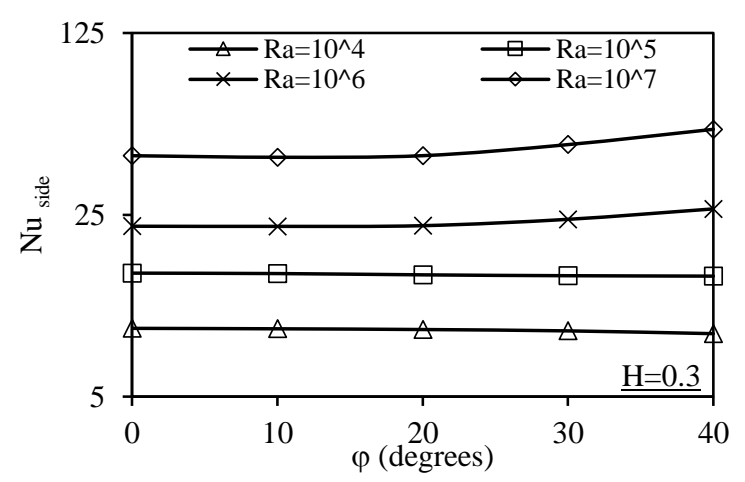

(a)

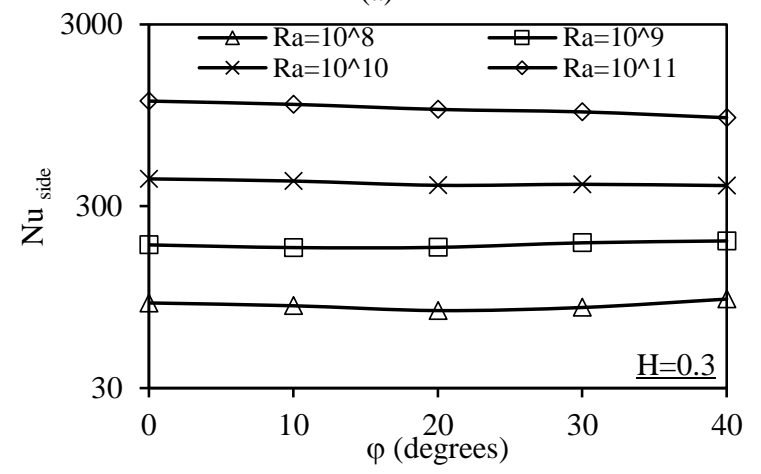

(b)

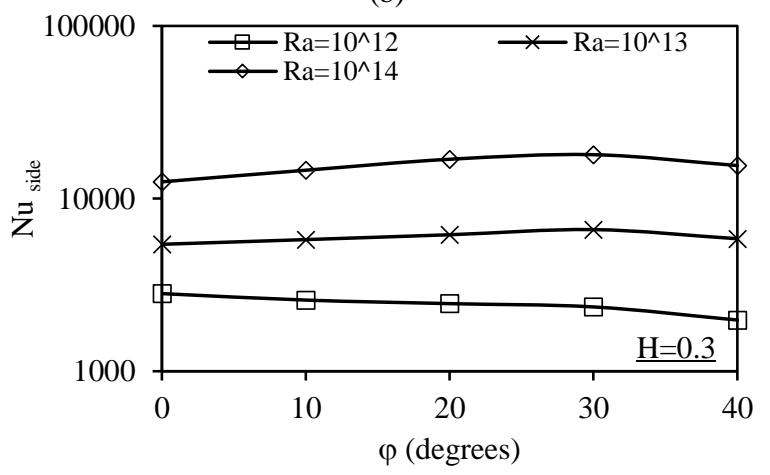

(c)

Fig. 11 Variations of the mean Nusselt number for the side surface of the plate with diagonal inclination angle for (a) lower Rayleigh numbers, (b) intermediate Rayleigh numbers and (c) higher Rayleigh numbers considered for a dimensionless plate thickness, $\mathrm{H}$, of 0.3 . 


\section{EXPERIMENTAL APPARATUS AND PROCEDURE}

The purpose of the experiments conducted in the present study was to validate the numerical model used to obtain the heat transfer results for the diagonally inclined two-sided square plate. In the experimental study, the heat transfer rate from the plate considered was determined using the lumped capacity method.

\subsection{Apparatus}

To measure the heat transfer rate from the two-sided plate a support frame on which the plate is mounted was used. The support frame plates were made from a Plexiglas and the supporting elements on which the plate was mounted were made from steel and had a sharply pointed tip to make the contact area with the heated plate as small as possible. The frame assembly was located on a leveled horizontal table. The experiments were undertaken in a large test chamber located inside a closed laboratory to avoid the temperature changes and air disturbance that could interfere with the flow over the plate. The heated plate used in the experimental study was made from aluminum alloy ( $\mathrm{Al}$ 6061-T6) and had a width, $w$, of $0.2 \mathrm{~m}$ and a dimensionless thickness, $\mathrm{H}$, of 0.0635 . Thermocouples, which were previously calibrated were embedded into holes drilled into the side surface of the plate were used to measure the temperature of the plate.

\subsection{Experimental Procedure}

The heat transfer rate from the square plate in the situation being considered was determined using the lumped capacity method. The method involves heating the plate up using an electric oven to a temperature of roughly $100^{\circ} \mathrm{C}$ above ambient. The plate was then removed from the oven and allowed to cool to a temperature of about $15^{\circ} \mathrm{C}$ above ambient. The transient variation of the plate temperature as it cools was measured and recorded over the selected temperature range using a data acquisition system. The cooling time interval was divided into 5 minutes subintervals. From the transient temperature variation, and the specific heat of the plate material, and if the plate temperature was assumed to be uniform at any time instant during cooling process, the overall heat transfer coefficient, $h_{t}$, can then be calculated using the following equation:

$h_{t}=\frac{m c}{A_{\text {total }} t} \ln \left[\frac{\left(T_{i}-T_{f}\right)}{\left(T_{e}-T_{f}\right)}\right]$

To check the plate temperature uniformity, it is usual to assume that if Biot number, $B i$, is less than 0.1, the uniform body temperature assumption can be used. In all experimental tests, the values of Biot number obtained were much less than 0.1 , therefore, the lumped capacity method could be used with an acceptable accuracy.

The overall heat transfer coefficient given by Eq. (10) involves convection and radiation from plate to the surrounding and conduction to the supporting elements on which the plate is mounted. The conduction heat transfer is assumed to be negligible due to the very small area of contact the plate makes with the supporting frame elements. To correct for radiation, if the body is assumed too small compared with the surroundings to which it is radiating, then the radiant heat transfer coefficient for each time interval is given by:

$h_{r}=\sigma \varepsilon\left(T_{m}^{2}+T_{s}^{2}\right)\left(T_{m}+T_{s}\right)$

where, $\varepsilon$ is the emissivity of the aluminum plate which is assumed to be 0.1 according to the plate surface finish, $T_{m}$ is the mean temperature of the plate during the time interval considered, i.e., $T_{m}=\left(T_{i}+T_{e}\right) / 2$, and $T_{S}$ is the temperature of the surroundings to which the body is radiating ( $T_{s}=T_{f}$ for the type of situations being considered here). Equation (11) can, therefore, be rewritten as: $h_{r}=\sigma \varepsilon\left(\left(\frac{\left(T_{i}+T_{e}\right)}{2}\right)^{2}+T_{f}^{2}\right)\left(\frac{\left(T_{i}+T_{e}\right)}{2}+T_{f}\right)$

On average, the radiative heat transfer coefficient was approximately 11 per cent of the total heat transfer coefficient for the diagonal inclination angles considered.

As a result, the convective heat transfer coefficient can be calculated using the following equation:

$h_{c}=h_{t}-h_{r}$

The above procedure was applied for each diagonal inclination angle considered, i.e., for $\varphi=0^{\circ}, 10^{\circ}, 20^{\circ}, 30^{\circ}$, and $40^{\circ}$.

\subsection{Uncertainty Analysis}

The possible errors in various quantities being measured contribute in the uncertainties in the experimental results (uncertainty propagation). An uncertainty analysis was, therefore, performed to give the interval within which an error in the measured value lies. The overall uncertainty in Nusselt number has been determined using the root-sum-square (RSS) method, see (Kline and McClintock, 1953). The relative uncertainty range for the experimental values of Nusselt number at every diagonal inclination angle and over the time interval considered was obtained.

\section{EXPERIMENTAL DATA AND COMPARISON WITH NUMERICAL RESULTS}

As explained earlier, the experimental data were obtained to validate the numerical model used. A comparison between the numerical results and the experimental data when the dimensionless plate thickness, $\mathrm{H}$, is 0.0635 for various diagonal inclination angles considered is shown in Fig. 12. It should be noted here that the Rayleigh numbers range is a bit different in this figure because of the difference in the ambient temperature during the experiment for each diagonal inclination angle. It can be seen from this figure that for the diagonal inclination angles considered the numerical results obtained lie within the experimental uncertainty (error band of the experimental results) which is at most less than 11 per cent and good agreement was obtained except when the diagonal inclination angle is $40^{\circ}$, the numerical results, however, lie outside of the experimental uncertainty range. This is possibly due to inaccurate prediction by the numerical model of when transition to turbulence starts to occur. Nevertheless, the maximum percentage difference between the experimental data and numerical results for this angle $\left(40^{\circ}\right)$ is less than 14 per cent for the range of Rayleigh number considered. Table 2 shows the mean and maximum percentage differences between numerical and experimental mean Nusselt numbers for various diagonal inclination angles considered.

Table 2 Percentage difference between numerical and experimental mean Nusselt number.

\begin{tabular}{ccc}
\hline $\begin{array}{c}\text { Angle } \\
\text { (degrees) }\end{array}$ & $\begin{array}{c}\text { Mean } \\
\text { \% difference }\end{array}$ & $\begin{array}{c}\text { Maximum } \\
\text { \% difference }\end{array}$ \\
\hline 0 & 1.5964 & 6.5011 \\
10 & 1.9647 & 3.3329 \\
20 & 1.9970 & 4.3564 \\
30 & 1.3126 & 4.0514 \\
40 & 10.3058 & 13.1192 \\
\hline
\end{tabular}




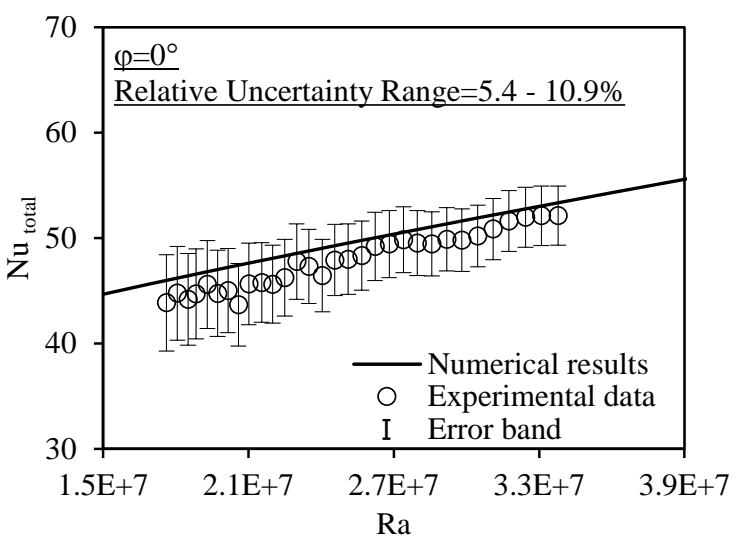

(a)

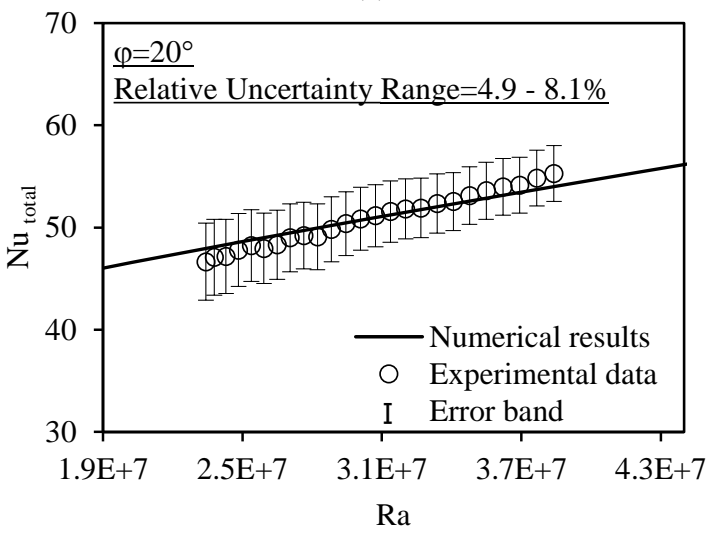

(c)

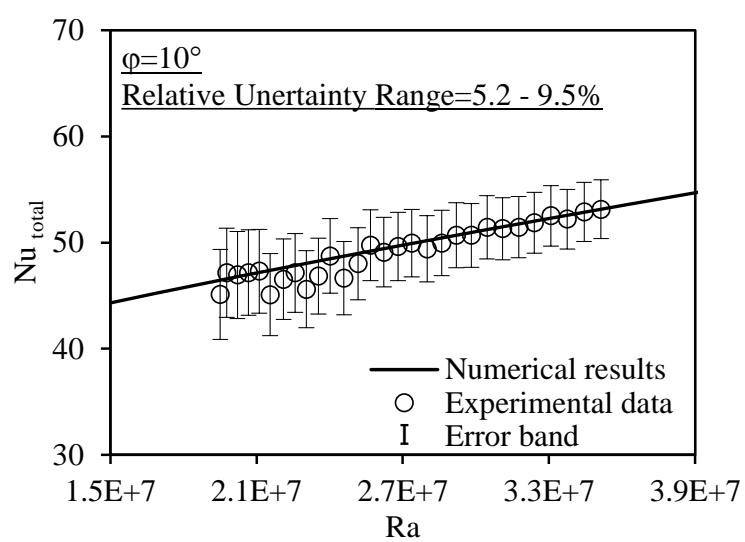

(b)

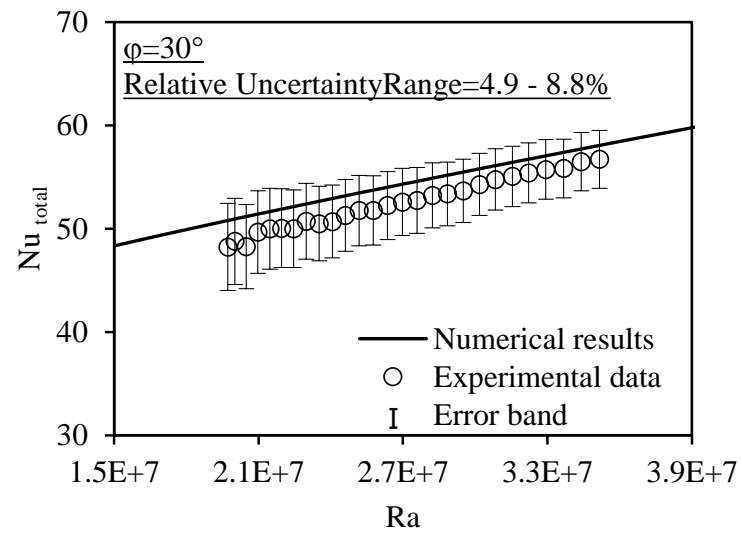

(d)

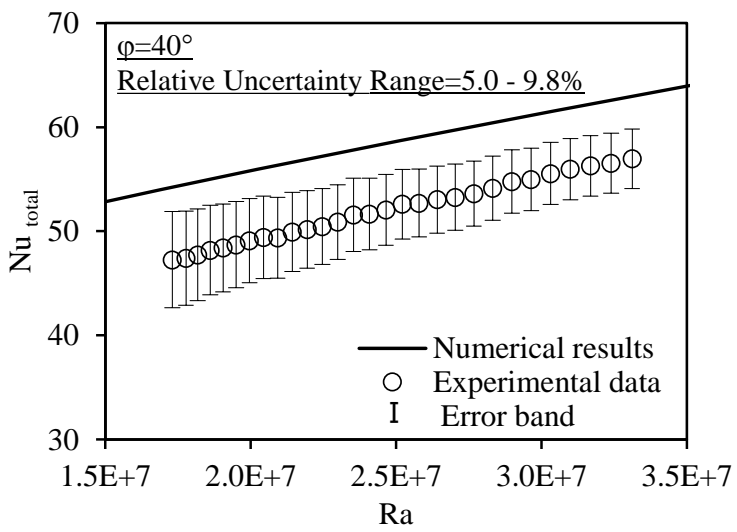

(e)

Fig. 12 Comparison of the numerical results with the experimental data for diagonal inclination angle of (a) $0^{\circ}$, (b) $10^{\circ}$, (c) $20^{\circ}$, (d) $30^{\circ}$, and (e) $40^{\circ}$ for dimensionless plate thickness, $\mathrm{H}$, of 0.0635 . The relative uncertainty range is shown for each diagonal inclination angle.

\section{SUMMARY AND CONCLUSIONS}

Numerical and experimental results have been obtained for natural convective heat transfer from two-sided diagonally inclined square plates having various thicknesses for various diagonal inclination angles. In all cases it is found that the heat transfer rate from the top surface is lower than that for the bottom surface at the lower Rayleigh number values considered but is higher than that for the bottom surface at the higher Rayleigh number values. The dimensionless plate thickness has an almost negligible effect on the heat transfer rate from the bottom surface but has a significant effect for the top surface especially at lower values of dimensionless plate thickness, the nature of this effect being dependent on the Rayleigh number value considered. The effect of the dimensionless plate thickness on the heat transfer rate is also significant for the side surface of the plate for the range of Rayleigh numbers considered except at higher values of Rayleigh number. The diagonal inclination angle has a significant effect on the heat transfer rate from the top and side surfaces for the range of Rayleigh numbers considered while this effect is significant for the bottom surface only at higher values of Rayleigh numbers. The numerical results lie within the uncertainty of the experimental data which is at most less than 11 per cent. The only exception, however, is at diagonal inclination angle of $40^{\circ}$ where the numerical results lie outside of the experimental uncertainty. 


\section{ACKNOWLEDGEMENT}

This work was supported by the Natural Sciences and Engineering Research Council of Canada (NSERC) through its Discovery Grant Program (Grant RGPIN-2015-06444).

\section{NOMENCLATURE}

$A_{\text {plate }} \quad$ area of the top surface of plate and of bottom surface of plate $\left(\mathrm{m}^{2}\right)$

$A_{\text {side }} \quad$ area of the side surface of plate $\left(\mathrm{m}^{2}\right)$

$A_{\text {total }} \quad$ sum of the areas of the heated surfaces of plate $\left(\mathrm{m}^{2}\right)$

$\mathrm{Bi} \quad$ Biot number

C specific heat of material from which plate is made $(\mathrm{J} / \mathrm{kgK})$

$g \quad$ gravitational acceleration $\left(\mathrm{m} / \mathrm{s}^{2}\right)$

$h \quad$ thickness of plate $(\mathrm{m})$

$h_{t} \quad$ total heat transfer coefficient $\left(\mathrm{W} / \mathrm{m}^{2} \mathrm{~K}\right)$

$h_{r} \quad$ radiant heat transfer coefficient $\left(\mathrm{W} / \mathrm{m}^{2} \mathrm{~K}\right)$

$h_{c} \quad$ convective heat transfer coefficient $\left(\mathrm{W} / \mathrm{m}^{2} \mathrm{~K}\right)$

$H \quad$ dimensionless thickness of plate, $h / w$

$k \quad$ thermal conductivity $(\mathrm{W} / \mathrm{mK})$

$m \quad$ mass of plate $(\mathrm{kg})$

$\mathrm{Nu}$ mean Nusselt number

$\mathrm{Nu} u_{\text {total }}$ mean Nusselt number based on the mean heat transfer rate per unit area over heated surfaces of plate

$N u_{\text {top }} \quad$ mean Nusselt number based on the mean heat transfer rate per unit area over upper surface of plate

$N u_{\text {bot }} \quad$ mean Nusselt number based on the mean heat transfer rate per unit area over lower surface of plate

$N u_{\text {side }} \quad$ mean Nusselt number based on the mean heat transfer rate per unit area over side surface of plate

Pr Prandtl number

$\overline{Q^{\prime}} \quad$ total heat transfer rate from the heated surfaces of plate $(\mathrm{W})$

$\bar{Q}_{\text {top }}{ }^{\prime}$

${\overline{Q^{\prime}}}_{\text {bot }}$

$\bar{Q}_{\text {side }}^{\prime}$

$R a$

$t$

$T_{w}$

$T_{f}$

$T_{i}$

$T_{e}$

$T_{m}$

$T_{s}$

W total heat transfer rate from the upper surface of plate (W) total heat transfer rate from the lower surface of plate (W) total heat transfer rate from the side surface of plate (W) Rayleigh number time (s) temperature of heated surfaces of plate $(\mathrm{K})$ temperature of fluid far from plate $(\mathrm{K})$ initial temperature of plate $(\mathrm{K})$ final temperature of plate $(\mathrm{K})$ mean temperature of plate $(\mathrm{K})$ temperature of the surroundings to which body is radiating $(\mathrm{K})$ side length of square plate $(\mathrm{m})$

Greek Symbols

$\varphi \quad$ diagonal inclination angle (degrees)

$\alpha \quad$ thermal diffusivity $\left(\mathrm{m}^{2} / \mathrm{s}\right)$

$\beta \quad$ bulk coefficient of expansion $(1 / \mathrm{K})$

$v \quad$ kinematic viscosity $\left(\mathrm{m}^{2} / \mathrm{s}\right)$

$\sigma \quad$ Stefan-Boltzmann constant $\left(\mathrm{W} / \mathrm{m}^{2} \cdot \mathrm{K}^{4}\right)$

$\varepsilon \quad$ emissivity of plate

\section{REFERENCES}

Al-Arabi, M., and Sakr, B., 1988, "Natural Convection Heat Transfer from Inclined Isothermal Plates," International Journal of Heat and Mass Transfer, 31(3), 559-566. https://dx.doi.org/10.1016/0017-9310(88)90037-3

Albets-Chico, X., Oliva, A., and Perez-Segarra, C.D., 2008, "Numerical Experiments in Turbulent Natural Convection Using Two-Equation Eddy-Viscosity Models," Journal of Heat Transfer, 130(7), 072501-1072501-11.

https://dx.doi.org/10.1115/1.2907432
Churchill, S.W., and Chu, H.H., 1975, "Correlating Equations for Laminar and Turbulent Free Convection from a Vertical Plate," International Journal of Heat and Mass Transfer, 18(11), 1323-1329. https://dx.doi.org/10.1016/0017-9310(75)90243-4

Corcione, M., Habib, E., and Campo, A., 2011, "Natural Convection from Inclined Plates to Gases and Liquids when Both Sides are Uniformly Heated at the Same Temperature," International Journal of Thermal Sciences, 50(8), 1405-1416.

https://dx.doi.org/10.1016/j.ijthermalsci.2011.03.012

Hassan, K.E., and Mohamed, S.A., 1970, "Natural Convection from Isothermal Flat Surfaces," International Journal of Heat and Mass Transfer, 13(12), 1873-1886.

https://dx.doi.org/10.1016/0017-9310(70)90090-6

Kalendar, A., Kalendar, A.Y., and Alhendal, Y., 2016, "Evaluation of Turbulence Models for Natural and Forced Convection from Flat Plates," Computational Thermal Sciences: An International Journal, 8(6), 567582.

https://dx.doi.org/10.1615/ComputThermalScien.2016018660

Kline, S.J., and McClintock, F.A., 1953, "Describing Uncertainties in Single-Sample Experiments," Mechanical Engineering, 75(1), 3-8.

Kobus, C.J., and Wedekind, G.L., 2002, “An Empirical Correlation for Natural Convection Heat Transfer from Thin Isothermal Circular Disks at Arbitrary Angles of Inclination," International Journal of Heat and Mass Transfer, 45(5), 1159-1163.

https://dx.doi.org/10.1016/S0017-9310(01)00213-7

Manna, R., and Oosthuizen, P.H., 2019, "Numerical and Experimental Studies of Natural Convective Heat Transfer from Two-Sided Diagonally Inclined Square Plates Having a Finite Thickness," Proceedings of the $14^{\text {th }}$ International Conference of Heat Transfer, Fluid Mechanics and Thermodynamics (HEFAT), Wicklow, Ireland.

Oosthuizen, P.H., 2014, "Natural Convective Heat Transfer from an Inclined Isothermal Square Flat Element Imbedded in a Flat Adiabatic Surrounding Surface," IHTC15-8499/NCV-F-424, Proceedings of the $15^{\text {th }}$ International Heat Transfer Conference (IHTC), Kyoto, Japan. https://dx.doi.org/10.1615/IHTC15.ncv.008499

Pera, L., and Gebhart, B., 1973, "Natural Convection Boundary Layer Flow over Horizontal and Slightly Inclined Surfaces," International Journal of Heat and Mass Transfer, 16(6), 1131-1146.

https://dx.doi.org/10.1016/0017-9310(73)90126-9

Plumb, O.A., and Kennedy, L.A., 1977, “Application of a $k-e$ Turbulence Model to Natural Convection from a Vertical Isothermal Surface," Journal of Heat Transfer, 99(1), 79-85. https://dx.doi.org/10.1115/1.3450659

Savill, A.M., 1993, "Evaluating Turbulence Model Predictions of Transition," An ERCOFTAC special interest group project, Applied Scientific Research, 51(1-2), 555-562. https://dx.doi.org/10.1007/BF01082590

Schmidt, R.C., and Patankar, S.V., 1991, "Simulating Boundary Layer Transition with Low-Reynolds-Number $k-\varepsilon$ Turbulence Models: Part 1An Evaluation of Prediction Characteristics," Journal of Turbomachinery, 113(1), 10-17. https://dx.doi.org/10.1115/1.2927728

Wei, J.J., Yu, B., Wang, H.S., and Tao, W.Q., 2002, "Numerical Study of Simultaneous Natural Convection Heat Transfer from Both Surfaces of a Uniformly Heated Thin Plate with Arbitrary Inclination," Journal of Heat and Mass Transfer, 38(4-5), 309-317. https://dx.doi.org/10.1007/s002310100276

Xamán, J., Álvarez, G., Lira, L., and Estrada, C., 2005, "Numerical Study of Heat Transfer by Laminar and Turbulent Natural Convection in Tall Cavities of Façade Elements," Energy and Buildings, 37(7), 787-794. https://dx.doi.org/10.1016/j.enbuild.2004.11.001 